\title{
New approach to approving natural health products inadequate, says British Columbia Medical Association
}

$\mathrm{A}$ new streamlined approach to evaluating and authorizing natural health products in Canada is not rigorous enough, according to the British Columbia Medical Association.

In 2010, Health Canada brought in the Unprocessed Product License Applications Regulations, which allowed "lower-risk products" to be legally sold while their applications were under review.

The new approach will focus on getting products authorized in a faster and simpler way. As of Feb. 4, product licensing decisions will be made in 180 days or less, and decisions on certain types of products will be made within 30 days.

"The process for evaluating the claims of effectiveness and safety of natural health products was far too low to begin with," says Dr. Lloyd Oppel, the British Columbia Medical Association's (BCMA) spokesman on alternative medicine.

"Streamlining the process is not going to help that situation and we [at the BCMA] feel that really there should be compelling scientific evidence of effectiveness of these products before they're allowed to make the claims to begin with, and that type of constraint simply doesn't exist in natural health products."

In total, there have been 60750 licenced natural health products in Canada, with more than 5000 of those being approved in the past six months, according to Health Canada.

Safety for consumers is the main concern of the initiative, Parliamentary Secretary of Health, Dr. Colin Carrie, said at the announcement of the new system at the Canadian Health Food Association Trade Show in Montréal, Que. on Feb. 2.

"We're all in favour of new products - pharmaceutical, natural, devices - anything that actually works and is safe," says Oppel. "But we also have learned some very hard lessons historically that you actually need to check things out properly before you can make that assumption."

With this new streamlined approach, the regulatory system will shift its

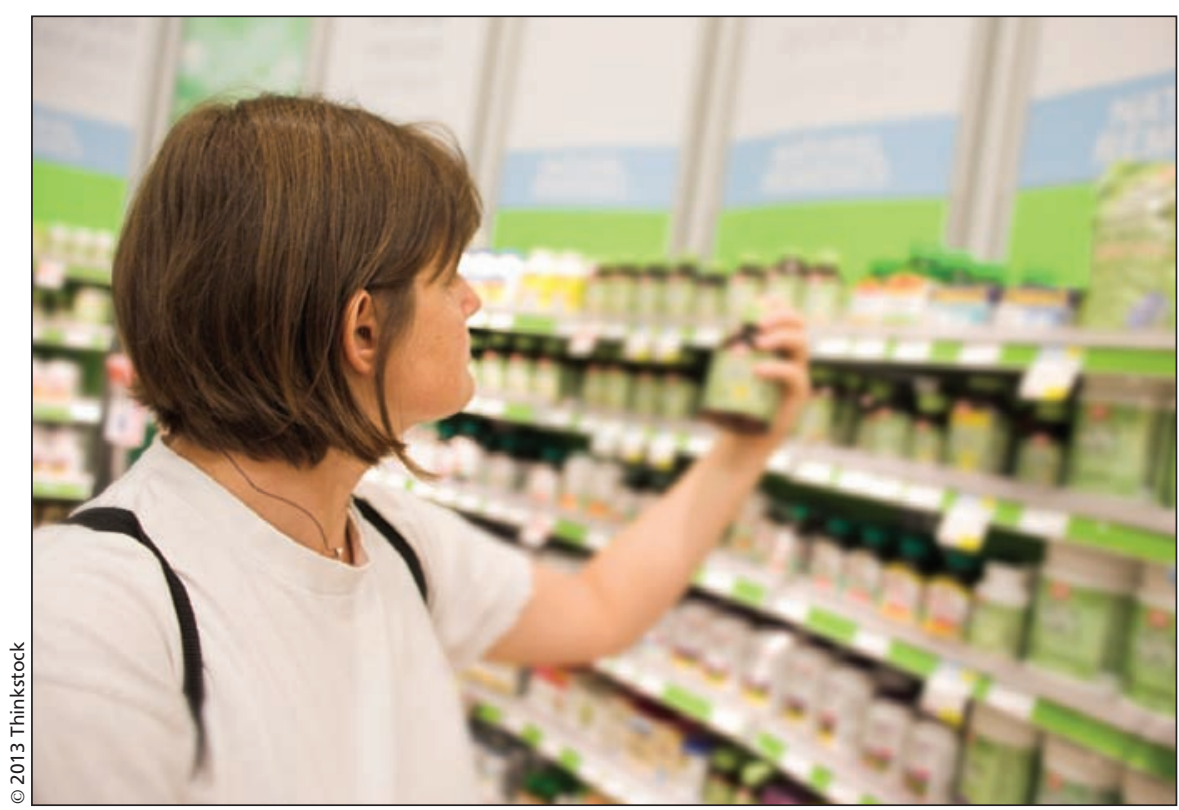

There are 60750 licenced natural health products in Canada, with more than $\mathbf{5 0 0 0}$ of those being approved in the past six months, according to Health Canada.

focus to evaluating complex products and those about which Health Canada has the least information.

Health Canada has now amassed information from authorizing more than 60000 natural health products, says Sara Lauer, a spokesperson for Health Canada.

"Our new approach provides better tools (policies and process improvements) to our evaluation staff, and to industry, to harness that knowledge," Lauer writes in an email.

"This has led to a more efficient, consistent and robust evaluation of products in all categories and reduces the review times for products for which we have the most information."

According to Health Canada, the reductions in review times will not change the measures in place to protect consumers, as the level of evidence required to prove products are safe remains the same and products will still be labelled with required cautionary statements.

In addition to this, companies that manufacture the products will still be required to submit reports of serious adverse reactions to Health Canada, which will continue to monitor these reactions through the Canada Vigilance Program.

Oppel says that this postmarketing surveillance program can pick up some things that have immediate adverse effects, "but things like cancer and longterm effects on other organs, it's just not possible to get a reliable picture in postmarket surveillance.'

In an effort to improve this monitoring system, Health Canada is also developing new tools for monitoring natural health product adverse reactions within the Canada Vigilance Program, Lauer writes in an email, but the specifics of these tools have not yet been released.

"I think there should be some process of review, but even the process of review that we've got now is still inadequate," says Oppel.

"The only people that this is really good for are the vendors who do not have to undertake the expensive rigorous safety or effectiveness testing," he adds. "So in some ways this is a gift to industry to do things in this way - it certainly does nothing to protect consumers."-_Adam Miller, CMAJ 